\title{
EL REGRESO DE BRADLEY Y EL PROBLEMA DE LA UNIDAD-COMPLEJA: ¿TROPOS AL RESCATE?
}

\author{
SEBASTIÁn BRiceño \\ Universidad de Concepción \\ jsbricen@gmail.com
}

\begin{abstract}
RESUMEN: Suele sostenerse que el regreso de Bradley admite solución dentro de una ontología de tropos. Esto pareciera suceder cuando a un cúmulo se le entiende como constituido por tropos no transferibles. También pareciera suceder cuando un cúmulo es entendido como constituido por tropos transferibles relacionados por un tropo relacional de copresencia cuya existencia dependa específicamente de dichos relata. En este artículo demuestro que estas propuestas no se hacen cargo de la cuestión esencial que subyace al regreso, cayendo en una petición de principio ya anticipada por Bradley.
\end{abstract}

PALABRAS CLAVE: objetos, propiedades, relaciones, identidad, copresencia

SUMMARY: It is commonly held that Bradley's regress has a solution within a tropeontology. This seems to happen when a bundle is understood as constituted by non-transferable tropes. It also seems to happen when a bundle is understood as constituted by transferable tropes related by a relational trope of compresence whose existence specifically depends on those relata. In this article I demonstrate that these proposals fail in addressing the essential question that underlies the regress, incurring in a question-begging response already anticipated by Bradley.

KEY WORDS: objects, properties, relations, identity, compresence

\section{Introducción}

Según las apariencias, el mundo que nos rodea no es una unidad simple e indiferenciada, un todo parmenideano. Tampoco es una mera pluralidad de unidades simples e indiferenciadas, varios átomos democriteanos. Las apariencias nos revelan unidad y complejidad, singularidad y pluralidad a la vez. Y este doble carácter parece ser poseído por todo lo que nos rodea: el mundo parece ser una unidadcompleja de unidades-complejas. Pensemos en un árbol. Ese árbol se nos presenta como parte de otras unidades-complejas (un bosque, un paisaje, un jardín botánico) y tomado singularmente también se nos presenta como una unidad-compleja (está compuesto de tronco, ramas y hojas; es frondoso, rugoso y aromático). Y lo que vale para el árbol vale para todo lo aparente: frutas, perros, libros, constelaciones, guerras, sinfonías, oraciones, etc. Por donde miremos hay, simultáneamente, unidad y complejidad. No mera unidad o simplicidad; no mera complejidad o pluralidad. Si el mundo fuese en realidad como 
el de Parménides o el de Demócrito, entonces ellos nos deberían una explicación sobre cómo es que dicho mundo da lugar a las apariencias que nos rodean.

Un problema fundamental para toda metafísica que postula la existencia de algún objeto complejo es el problema que obsesionó a Bradley: ¿cómo es que una singularidad es una pluralidad? El regreso de Bradley es una de las estrategias que usó el filósofo británico para bloquear una posible respuesta a ese problema, aquella que recurre a relaciones como unificadores de constituyentes distintos. Muchos creen que el regreso sólo se desencadena cuando buscamos lograr la unidad de entidades ontológicamente independientes mediante otra entidad ontológicamente independiente. Descansando en esta creencia, hay quienes sostienen que el regreso puede ser bloqueado dentro de una ontología mono-categorial de tropos, o al menos dentro de algunas versiones de ésta. Esto pareciera suceder, por ejemplo, si los tropos monádicos de un cúmulo son entendidos como no transferibles o recíprocamente dependientes. También pareciera suceder si los tropos monádicos de un cúmulo son entendidos como transferibles u ontológicamente independientes, pero se recurre a un tropo relacional de copresencia multidependiente de sus relata como agente unificador. En este artículo demuestro que estas propuestas basadas en tropos fracasan, y sólo encubren una petición de principio ya anticipada por Bradley, y su aparente éxito sólo revela una incomprensión o un ocultamiento de la cuestión esencial que subyace al regreso: el problema de la unidad-compleja y la incapacidad de cualquier relación para resolverlo.

\section{El problema de la unidad-compleja y el lugar del regreso de Bradley}

El regreso de Bradley es sólo una arista de un argumento más complejo destinado a demostrar que la existencia de un objeto que sea idéntico a varios objetos es un sinsentido que pertenece a las apariencias y no a la realidad. Semejante sinsentido se daría, por ejemplo, cuando se sostiene que una cosa es diversas propiedades o que un todo es diversas partes. El argumento de Bradley demostraría, mediante una reductio, que en realidad sólo existe un objeto y que la complejidad (partes, sustratos, propiedades, relaciones, etc.) es mera apariencia, el resultado de cierto proceso de "abstracción viciosa" en el que incurre el pensamiento debido a la forma incorregiblemente fragmentaria y relacional en que intenta capturar la realidad. Las abstracciones así obtenidas no tendrían un estatus ontológico superior al de una ficción 
de descomposición. Aquí no exploraré el detalle de las fantásticas consecuencias positivas que parecen seguirse del argumento de Bradley ni si acaso efectivamente se siguen (para ello, véanse Basile 1999; Blanshard 1984; Candlish 2007; Hylton 1990; Sprigge 1983; Valicella 2002). Sin perjuicio de que al final, al intentar esbozar las bases para una posible salida, diré algo al respecto, quiero concentrarme mayormente en defender el poder destructivo del argumento frente a las variantes más relevantes de una solución según la cual es posible aceptar sus premisas pero resistir sus consecuencias.

Siguiendo la detallada y convincente exégesis que Baxter (1996) ha ofrecido, podemos decir que el argumento de Bradley admite ser reconstruido como un trilema. Los tres cuernos están dados por las tres posibles respuestas, conjuntamente exhaustivas, mutuamente excluyentes e igualmente insatisfactorias, a lo que Baxter llama "el problema de la unidad-compleja". Para empezar, Bradley recurre a un terrón de azúcar: "Esto es una cosa, y tiene propiedades, adjetivos que la cualifican. Es, por ejemplo, blanco, y duro, y dulce. El azúcar, decimos, es todo eso; pero lo que el es puede realmente significar parece dudoso" (1930, p. 16; las cursivas son del original). ${ }^{1}$

Todo indica que Bradley está pensando en el es de identidad o, como diría un escolástico, en el es que figura en la definición real de un objeto, i.e., el enunciado de identidad que define la cosa (no su nombre ni su concepto) en términos informativos, consistentes y verdaderos. Bonino (2013) y Maurin $(2010,2012)$, correctamente, aprueban esta interpretación de Baxter (1996). Lo que hace que el significado de es le parezca dudoso a Bradley no es que él dude de que ese es esté por el es de identidad, sino que parece no haber forma alguna en que la aserción de identidad en cuestión pueda de hecho expresar algo que sea informativo, consistente y verdadero. Cuando intentamos expresar lo que un objeto singular es, yendo más allá de la trivialidad según la cual dicho objeto es idéntico a sí mismo, nos vemos envueltos en falsedades o contradicciones, pues "si predicas lo que es diferente entonces adscribes al sujeto lo que el sujeto no es; y si predicas lo que no es diferente, no dices nada en absoluto" (Bradley 1930, p. 17; las cursivas son del original).

Para ser más precisos, el problema de la unidad-compleja puede ser formulado así: ¿cómo es posible que una entidad sea numéricamente idéntica a una pluralidad de entidades? Parece tratarse de un genuino problema porque aceptar una unidad-compleja parece

\footnotetext{
${ }^{1}$ Las traducciones de todas las citas de este artículo son mías.
} 
llevarnos a admitir algo que tiene todos los visos de una contradicción: ¿cómo puede ser que una misma cosa sea una y varias, esto es, no una? ${ }^{2}$ Para plantear el trilema, sigamos usando el ejemplo que Bradley utiliza, el del terrón de azúcar. Para efectos del argumento, entendamos su estructura ontológica tal como un teórico de tropos y cúmulos lo haría, a saber: un terrón de azúcar es un objeto particular, concreto y complejo constituido por varios objetos particulares, abstractos y simples: un cúmulo de varios tropos. ${ }^{3}$ Así, podemos decir que nuestro terrón de azúcar es blanco, duro y dulce. En aras de la simpleza, asumamos que estas tres cualidades son todas las que el terrón de azúcar tiene. Aceptado que la estructura ontológica del terrón de azúcar es la de un cúmulo de varios tropos, decir que esos varios tropos inhieren en el terrón de azúcar es simplemente otra forma de decir que esos varios tropos son el terrón de azúcar. En este caso, inherencia, como bien entiende Bradley, es sólo otra palabra para

${ }^{2}$ El problema, al menos en este caso, no es cómo la cosa está fundada, como Schaffer $(2009,2010)$ cree. Una entidad puede estar metafísicamente fundada en (o supervenir sobre, o depender ontológicamente de) otra entidad numéricamente distinta, como cuando algunos dicen que cierto fragmento de realidad alética depende de otro fragmento de realidad no alética. Pero esto no da cuenta de cómo está metafísicamente hecha o compuesta una cosa, como cuando decimos que Agua $=\mathrm{H}_{2} \mathrm{O}$. En el primer caso no se explica lo que los relata son, sino cómo están relacionados, y la relación entre lo fundado y su fundamento es asimétrica e irreflexiva. En el segundo caso hay identidad explicatoria de un único relatum, explicación de lo que una misma cosa es, y la relación entre explanans y explanandum es simétrica y reflexiva, pues la relación no es otra que la de identidad. No tiene sentido decir que una bicicleta está fundada en todas-sus-partes-dispuestas-bicicletísticamente, o vice-versa, pues la bicicleta no es distinta a todas-sus-partes-dispuestas-bicicletísticamente. Pace Schaffer, el todo y sus partes no están en relación de dependencia asimétrica e irreflexiva. El todo es sus partes en determinado arreglo, y viceversa. Composición es identidad (cfr. Baxter 1988).

${ }^{3}$ Parto comprendiendo el terrón de azúcar como un cúmulo de tropos simplemente para efectos argumentales, pues ésta es la forma en que los teóricos de tropos suelen comprender la estructura de un particular concreto ( $c f r$. Campbell 1990; Maurin 2010, 2012; Molnar 2003; Simons 1994; Williams 1953) y son las propuestas de solución que se han ofrecido desde esta ontología las que son objeto de mi crítica. Pero nada realmente serio depende de asumir esto. Pues el mismo problema se plantea para quien sostiene que una sustancia, estado de cosas o particular grueso es un sustrato o particular desnudo instanciando ciertas propiedades. El poder del argumento de Bradley afecta mutatis mutandis a toda teoría que pretenda dar cuenta de la estructura de una entidad en términos de varias entidades numéricamente distintas, sean éstas universales o particulares, abstracta o concreta. En efecto, también afecta a aquellos intentos nominalistas por desarrollar un cálculo de individuos en términos puramente mereológicos, pues, a fin de cuentas, un terrón de azúcar es un todo concreto compuesto por una pluralidad de partes concretas (viz., granos de azúcar), esto es, una entidad idéntica a varias entidades. 
designar esa identidad varios-uno. Teniendo nuestro terrón de azúcar como punto de partida, el trilema de Bradley puede formularse como sigue.

Primer cuerno. Una posibilidad es que al decir que nuestro terrón de azúcar es blanco, duro y dulce estamos diciendo que es idéntico a cada una de sus tres cualidades tomadas individualmente, una a una: nuestro terrón de azúcar entonces es idéntico a su blancura, es idéntico a su dureza y es idéntico a su dulzor. Y entonces decimos algo contradictorio. Pues si nuestro terrón de azúcar fuese simplemente idéntico a su dulzor, esto es, en palabras de Bradley, si fuese idéntico a "simplemente dulce", entonces "no sería dulce" (1930, p. 16), pues al ser idéntico a "simplemente dulce" no podría ser ni blanco ni duro, que son propiedades distintas: dulzor no es blancura ni dureza. Y lo mismo sucedería con "simplemente blanco" y con "simplemente duro". Nuestro terrón de azúcar, so pena de contradicción, no puede ser "simplemente dulce" si es que además de dulce es blanco y duro.

Segundo cuerno. Una segunda posibilidad es que al decir que nuestro terrón de azúcar es blanco, duro y dulce estamos diciendo que es idéntico a todas sus cualidades tomadas colectivamente. Nuestro terrón de azúcar es blancura, dureza y dulzor tomadas como varias, como una pluralidad de objetos numéricamente distintos. El obvio problema es que este camino sacrifica la supuesta unidad real del objeto en aras de su complejidad, su singularidad en aras de su pluralidad. Si tomamos este camino, no habría nada que nos permitiera distinguir entre la existencia de un terrón de azúcar y la existencia de una mera pluralidad de cualidades. La supuesta unidad del terrón podría ser vista, a lo más, como una ficción de composición, una forma de hablar o una mera proyección subjetiva. Pero nuestro terrón de azúcar "por supuesto no es la mera pluralidad de sus diferentes adjetivos", es decir, "obviamente no es mera blancura, mera dureza, y mero dulzor; pues su realidad descansa de alguna manera en su unidad" (Bradley 1930, p. 16).

Tercer cuerno. Podemos realmente abrazar una identidad unovarios, evitando contradicciones y falsedades, si traemos a escena algo que permita explicar claramente cómo es que varios objetos pueden ser idénticos a un objeto. Y la única candidata obvia para cumplir ese papel es una relación: "[Nuestro terrón de azúcar] no es, por supuesto, la mera pluralidad de sus diferentes adjetivos; pero, ¿por qué tendría que ser más que sus propiedades en relación? Cuando 'blanco', 'duro', 'dulce', y el resto coexiste en una determinada forma, ése es seguramente el secreto de la cosa. Las cualidades son, y son en relación" (Bradley 1930, p. 16). 
Ya que el terrón de azúcar no es la mera pluralidad de sus propiedades, se espera que sea una relación la que haga la diferencia entre una mera pluralidad y una unidad-compleja. El tipo de relación capaz de hacer tal cosa es lo que Baxter llama una "relación hacedora-deuno" (one-making relation) (1996, p. 11). El tercer cuerno entonces consiste en sostener que el terrón de azúcar es idéntico a varias propiedades en una determinada relación hacedora-de-uno. Llamémosla Rl. Y es aquí donde Bradley despliega su argumento del regreso $\mathrm{y}$, en general, su ataque contra el supuesto poder unificador de las relaciones. Ahora ya no decimos cosas sobre el terrón de azúcar; ahora decimos cosas sobre sus propiedades. Si antes dijimos "este terrón de azúcar es blanco, duro y dulce", ahora nos vemos en la obligación de decir que "blancura, dureza y dulzor están en una relación hacedora-de-uno". Pero, ¿qué significa "están" aquí? ¿Qué significa que blancura, dureza y dulzor "están" Rl-relacionadas? No avanzamos mucho si creemos que podemos eludir el problema mediante el reemplazo de la palabra "están" por palabras como "son" o "poseer" o "inherir", pues el significado de todas estas expresiones es el que está en cuestión ( $c f r$. Bradley 1930, p. 17). ¿Qué significa que varias propiedades "estén" o "sean" en Rl, o que Rl "inhiera" en, o sea "poseída" por, varias propiedades? Como se puede adivinar, aparece aquí, incubada en el tercer cuerno de nuestro trilema, una nueva versión del mismo trilema. Pues sucede que Rl es una entidad y las propiedades son varias entidades. $\mathrm{Y}$ es obvio que $\mathrm{Rl}$ no puede ser idéntica a las propiedades si las tomamos individualmente (primer cuerno). Tampoco puede ser idéntica a esas propiedades si las tomamos colectivamente (segundo cuerno). Sólo nos queda la posibilidad de que $\mathrm{Rl}$ sea una relación idéntica a varios objetos estando en una (jotra!) relación hacedora-de-uno (tercer cuerno). Y así, ad infinitum. El punto central de Bradley es que no hay tal cosa como una relación capaz de hacer de una pluralidad de entidades una entidad singular, pues sucede una de dos cuestiones:

(A) Una petición de principio. Uno puede detener la explicación sobre cómo una relación hacedora-de-uno relaciona ciertos relata diciendo: (i) que es de la naturaleza de dicha relación relacionar dichos relata; o (ii) que es de la naturaleza de dichos relata estar relacionados por dicha relación. Pero estas estrategias difícilmente pueden contar como explicaciones satisfactorias al problema de la unidad-compleja. Ambas estrategias suponen tratar lo que antes tenía una naturaleza simple (una relación, unos relata) ahora como unidades-complejas (una relación que incorpora a su naturaleza ciertos relata, unos relata 
que incorporan a sus naturalezas cierta relación). Así, Rl ya no es "simplemente R1" sino "Rl relacionando blancura, dureza y dulzor". Blancura ya no es "simplemente blancura" sino que es "blancura estando en Rl con dureza y dulzor". Si tomamos cualquiera de estos caminos, los mismos problemas que nos trajo el terrón de azúcar son ahora los que nos trae la relación, en el caso (i), o ciertos relata, en el caso (ii). Como es obvio, decir que una relación o una propiedad es una unidad-compleja nos obliga a responder nuevamente con una petición de principio o nos embarca en un regreso vicioso ( $c f r$. Bradley 1930, p. 26; 1935, p. 637), el regreso que veremos a continuación. Y es que la cuestión crucial es justamente qué queremos decir cuando decimos que esas propiedades "están" Rl-relacionadas, cómo es que Rl realmente unifica sus relata y, en general, cómo es que una relación de hecho relaciona. Ahora vemos que la invocación de una relación hacedora-de-uno trae de vuelta el mismo trilema que, se supone, estaba llamada a explicar. Es decir, invocar una relación hacedora-de-uno como fundamento ontológico de la unidad de los relata no tiene mayor poder explicatorio que decir que la relación hacedora-de-uno hace, de hecho, una entidad a partir de varias porque tiene el poder de hacerlo, o que las relaciones relacionan como lo hacen porque tienen el poder de relacionar como lo hacen. Con razón MacBride afirma que este tipo de estrategia para explicar cómo una relación relaciona descansaría en la poco iluminadora invocación de una "virtus relativa" (cfr. MacBride 2011, p. 170), pues explica tan mal o tan poco como la virtus dormitiva del opio explica por qué el opio hace dormir. Se trata de explicaciones que, sin ser falsas, resultan triviales, pues "no dice[n] nada en absoluto" (Bradley 1930, p. 17).

(B) Un regreso vicioso: El regreso de Bradley. Si intentamos evitar caer en la petición de principio antes descrita, caemos en un regreso vicioso, pues nos vemos obligados a invocar una nueva relación hacedora-de-uno (llamémosla R2) para explicar el poder unificador de Rl. Pero, como es evidente, la invocación de R2 nos conduce al mismo problema que la invocación de Rl. La incorporación de nuevas relaciones no hace sino transformar la pluralidad de objetos esperando por unidad en una pluralidad potencialmente infinita de objetos esperando por unidad, sin que ninguna de las relaciones a las que nos vemos obligados a recurrir demuestre su poder de hacer que varios sean uno. Lo que hacemos simplemente es incrementar la lista de objetos a la espera de unidad. Si para explicar la unidad de blancura, dureza y dulzor, invocamos R1, ahora, para explicar cómo R1 
une, nos vemos obligados a invocar R2 o a incurrir en una petición de principio. Y si optamos por invocar R2, al recibir la demanda por una explicación sobre cómo es que R2 une blancura, dureza, dulzor y Rl, nos vemos obligados a invocar una nueva relación hacedora-deuno, llamémosla R3, o a incurrir en una petición de principio. Y así, ad infinitum. ${ }^{4}$

\section{Universales}

Parece claro que el problema de Bradley se desencadena si es que Rl es concebida como un universal que representa adición ontológica independiente a sus relata, i.e., como una relación externa ( $f f r$. Armstrong 1978b, cap. 19; 1997, cap. 6; Lewis 1983b; Moore 1919; Rorty 1967). Y es que la mera existencia de R1, Blancura, Dureza y Dulzor no explica que Blancura, Dureza y Dulzor estén relacionados por Rl, pues Rl bien puede existir y ser lo que es relacionando otros relata distintos, y los primeros relata, a su vez, bien pueden existir y ser lo que son sin que Rl los relacione. ${ }^{5}$ Luego, si queremos realmente explicar por qué es que Blancura, Dureza y Dulzor están de hecho relacionados por $\mathrm{R} l$, entonces debemos recurrir a una relación distinta a R1, esto es, a R2. Pero siendo R2 una adición ontológica del mismo tipo que $\mathrm{R} l$, nos vemos embarcados en un regreso vicioso de relaciones u obligados a terminar la explicación con una petición de principio.

Como resulta evidente que las relaciones así comprendidas no parecen ser capaces de explicar cómo es que ellas de hecho relacionan,

${ }^{4}$ Como puede apreciarse, el carácter vicioso del regreso de Bradley no radica en la potencial infinitud de relaciones a las que da lugar, sino en la incapacidad de cada una de esas relaciones de relacionar sus términos. Éste es precisamente el punto del cual no se hacen cargo las soluciones que abrazan el infinitismo metafísico (e.g., Gaskin 2008; Morganti 2014; Orilia 2009). Es también el punto que distingue un regreso infinito vicioso, como el de Bradley, donde no se registra la prometida unidad en ningún paso, de otros regresos infinitos pero inofensivos, como el regreso de la verdad (si $\langle p\rangle$ es verdadera, entonces $\langle\langle p\rangle$ es verdadera $\rangle$ es verdadera, etc.), donde hay verdad en cada paso.

${ }^{5}$ En lo que sigue, cuando me refiera a propiedades entendidas como universales, utilizaré el nombre de la propiedad con la primera letra en mayúscula (e.g., Blancura); lo mismo valdrá para el cúmulo de los universales Blancura, Dureza y Dulzor (e.g., Terrón). En contraste, cuando me refiera a propiedades entendidas como tropos, agregaré subíndices numéricos al nombre respectivo (e.g., Blancural); lo mismo valdrá para el cúmulo de Blancura, Durezal $_{1}$ y Dulzor De.g., Terrón $_{1}$ ). Mientras Blancura es numéricamente idéntica en cada una de sus instanciaciones, Blancura $_{1}$ es perfectamente semejante pero numéricamente distinta a Blancura 2 . Y mientras Terrón ${ }_{1}$ es numéricamente distinto a Terrón 2 , en principio, Terrón es numéricamente idéntico a Terrón. 
los filósofos universalistas estiman que una forma no relacional de unión puede bloquear el regreso. Ésta ha sido en general la estrategia adoptada por quienes comprenden que un estado de cosas es una forma de composición no mereológica entre un particular desnudo y sus propiedades universales - aunque el razonamiento es perfectamente aplicable por analogía a otras formas de comprensión de unidades complejas, como aquellas que entienden que un objeto singular complejo es un cúmulo de propiedades, etc.- . Así, por ejemplo, Strawson ([1959] 2003, cap. 5) sostiene que lo que une particular y universal es un "vínculo no relacional" (non-relational tie). Y Armstrong (1978a, pp. 109-110; 1978b, p. 3; 1997, p. 115), siguiendo la tradición de Scotus, sostiene que la distinción entre particular desnudo y universal es una "distinción formal", algo así como una distinción que se sitúa entre una "distinción real" y una "distinción (meramente) conceptual". Por un lado, Armstrong pretende que su realismo inmanente sea capaz de distinguir realmente entre las propiedades y la particularidad de un particular. Por otro lado, también pretende que ese mismo realismo sea capaz de negar que estos dos aspectos están mediados por una relación. Para comprender esta "distinción formal", Armstrong nos invita a considerar la manera en que forma y tamaño están unidas en una figura $(c f r$. 1978a, pp. 109-110).

Pero la salida de Armstrong (tal como la de Strawson) no es satisfactoria. En primer lugar, decir que particular desnudo y universal están unidos por un "vínculo no relacional" o que particular desnudo y universal se distinguen sólo "formalmente", no prueba que aquello que estamos nombrando con nombres no relacionales no sea (o no presuponga la existencia de) una relación. Pues si forma y tamaño van de la mano en una figura es seguramente porque algo tiene una forma y porque ese mismo algo tiene un tamaño; y es difícil entender qué es ese "tiene" sino es en términos de una relación de instanciación o algo por el estilo. Lo mismo aplica para otro ejemplo al que recurre Armstrong: él dice que podríamos ilustrar cómo particular y universal van de la mano sin necesidad de recurrir a relaciones si es que en lugar de decir $<\mathrm{A}$ es verde $>$ simplemente escribiésemos "A" con tinta verde (cfr. Armstrong 1978a, p. 111). Pero nuevamente nos topamos con la misma dificultad, pues al escribir "A" con tinta verde lo que hacemos es simplemente representar la letra, el vínculo y su color al mismo tiempo. Y de ahí no se sigue que los distintos constituyentes de un objeto singular complejo o estado de cosas (particular, propiedad, instanciación) no existan o que no sean 
distintos, pues bien podemos escribir "A" con tinta roja y escribir "B" con tinta verde. Como argumenta Grossman, bien podemos usar múltiples medios de representación en lugar de la palabra "es", pero lo que parece claro es que, una vez que aceptamos particular desnudo y universal como distintos constituyentes de una unidad-compleja, algún medio de representación tendremos que usar para aquello que supuestamente los une ( $c f r$. Grossman 1982, p. 136).

Aun asumiendo que es posible unir constituyentes numéricamente distintos de una manera no relacional, o que es posible evitar la invocación de relaciones acudiendo a una mera "distinción formal" entre distintos constituyentes de una unidad-compleja, sucede que los constreñimientos propios del realismo inmanente de Armstrong no resultan suficientes para ello. Uno bien puede seguir a Armstrong (1978a, cap. 11) y argumentar que todo particular necesariamente instancia algún universal y que todo universal necesariamente es instanciado por algún particular. El problema es que, usando la expresión de Maurin, entre particular y universal existe, a lo más, "dependencia genérica": un tipo de entidad es ontológicamente dependiente de otro tipo de entidad. Pero el regreso de Bradley se genera en el intento de unir entidades específicas: este particular con este universal, no un tipo de entidad con otro tipo de entidad (cfr. Maurin 2010, p. 316). Así, la mera existencia de la letra A y del universal Verde no garantiza la existencia de la unidad-compleja que intenta representar la proposición $<\mathrm{A}$ es Verde $>$, pues aunque A tenga que ser necesariamente coloreada, y el color Verde tenga que colorear necesariamente a algún particular, de ahí no se sigue que A tenga que ser Verde. Bien podría ser el caso que tanto A como el color Verde existiesen $\sin$ que la proposición $<\mathrm{A}$ es Verde $>$ fuese verdadera, pues, por ejemplo, A podría haber sido Roja y el color Verde podría haber sido instanciado por la letra B. Extendiendo la estrategia de Armstrong a una ontología que entienda que los particulares concretos no son complejos de particulares desnudos y universales sino que simplemente son cúmulos de universales, uno podría aceptar que no hay universales que no constituyan algún cúmulo y que no hay cúmulos que no tengan universales como constituyentes. Pero ser constituyente de algún cúmulo no es lo mismo que ser constituyente de este cúmulo, de Terrón; y estar constituido por algún universal no es lo mismo que estar constituido por estos universales, por Blancura, Dureza y Dulzor. Por lo tanto, bien podrían existir los universales Blancura, Dureza y Dulzor y, sin embargo, no existir Terrón. El problema de Bradley es la unidad de ciertas entidades específicas y no de cierto tipo de entidades, por lo que una ontología según la cual 
algún universal siempre constituye algún cúmulo y algún cúmulo siempre es constituido por algún universal mal puede constituir una solución.

Ahora bien, con independencia de si las críticas anteriores son o no realmente eficaces, es común entre los teóricos de tropos asumir que sí lo son, y que éste es tanto un gran punto en contra de quienes conciben las propiedades como universales como un buen motivo para buscar otras alternativas. Veamos entonces qué nos pueden ofrecer los teóricos de tropos.

\section{Tropos no transferibles: la respuesta no relacional}

Viendo cómo fracasa el universalista, el defensor de tropos cree tener la solución al alcance de la mano, pues un tropo parece tener justamente el grado de dependencia específica que al universal le falta. Aunque postular la existencia de tropos no exige postular exclusivamente la existencia de tropos, es bastante común que, por razones de parsimonia ontológica, los teóricos de tropos se embarquen en una ontología mono-categorial (cfr. Campbell 1990; Maurin 2010, 2012; Molnar 2003; Simons 1994; Williams 1953). Así lo asumiré en lo que sigue. Ahora, dada una ontología mono-categorial de tropos, el problema de Bradley se traduce en cómo varios objetos particulares, abstractos y simples-Blancura, ${ }_{1}$, Dureza ${ }_{1}$, Dulzor $_{1}$-pueden ser $(=$ ser idénticos a) un objeto particular, concreto y complejo-Terrón ${ }_{l}$. Y aquí parece haber varias soluciones. Una primera alternativa es reflotar la estrategia no relacional recurriendo esta vez a entidades que no sólo sean genéricamente dependientes entre sí, sino que sean específicamente dependientes entre sí. En efecto hay quienes conciben a los tropos como entidades específicamente dependientes: un tropo no es una propiedad que pueda caracterizar a cualquier cúmulo, es decir, un tropo es una propiedad no transferible (en este sentido, por ejemplo, Molnar 2003). El rojo de esta flor no es el mismo rojo que el de esa flor. Rojo 1 no es idéntico a Rojo $o_{2}$, y cada uno de ellos caracteriza esencialmente una flor distinta. Esos dos tropos de color no existirían ni serían lo que son si no fuese porque caracterizan a sus respectivos cúmulos. La dependencia ontológica que exhiben los tropos de un mismo cúmulo es específica y, además, recíproca ( $c f r$. Fine 1995). Blancura 1 , Dureza 1 y Dulzor ${ }_{1}$ no podrían existir ni ser lo que son sino constituyendo Terrón ${ }_{1}$, y viceversa: Terrón $n_{1}$ no podría existir sin que Blancura ${ }_{1}$, Dureza y $_{1}$ Dulzor $_{1}$ existieran. Si los tropos son no transferibles en este sentido, entonces para que Blancura ${ }_{1}$, Dureza $_{1}$ y Dulzor garanticen la existencia de Terrón $_{1}$ ya ni siquiera 
es necesario invocar un tropo relacional de copresencia, pues presumiblemente bastaría la mera existencia de Blancura ${ }_{1}$, Dureza ${ }_{1}$ y

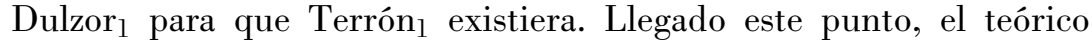
de tropos cree tener el camino despejado: siendo la dependencia ontológica entre tropos de un cúmulo específica y recíproca, no hay necesidad de recurrir a relaciones hacedoras-de-uno; y no existiendo la necesidad de recurrir a relaciones hacedoras-de-uno, el regreso de Bradley no tiene posibilidad de surgir como amenaza. Parece una solución; no lo es.

Antes de ver por qué la estrategia de recurrir a tropos no transferibles fracasa, veamos cuál es la usual reacción frente a ella. Dicha estrategia es generalmente rechazada no porque fracase en lidiar con el problema de Bradley sino porque trae consigo costos indeseables:

El precio es la enorme cantidad de necesidad in re que esta versión de la teoría de tropos debe postular. Toda propiedad y (pareciera ser) toda relación existente debe estar instanciada donde actualmente está instanciada. [...] Dados todos los particulares y todas las propiedadestropos y relaciones-tropos, el arreglo del mundo queda fijado. Si los particulares no son más que cúmulos de tropos, entonces dados solo los tropos individuales, propiedades y relaciones, el mundo queda fijado. (Armstrong 1997, p. 117)

Pareciera ser que el teórico de tropos que acepta tropos no transferibles tiene la ventaja de prescindir de la necesidad de invocar estados de cosas o relaciones de instanciación no supervenientes a la naturaleza de los relata ( $c f r$. Molnar 2003, pp. 45-46) y, gracias a ello, pareciera evitar abrir la puerta a la amenaza del regreso de Bradley. Pero el costo es una enorme cantidad de necesidad in re: el mundo no podría estar dispuesto de una forma distinta a la actual. ${ }^{6}$ El teórico

\footnotetext{
${ }^{6}$ Es tentador pensar que esta objeción podría ser sorteada si el teórico de tropos no transferibles adhiriese a una teoría de la modalidad de contrapartidas, tal como la de Lewis (1986). Así, dada la existencia actual de ciertos tropos no transferibles, no sería necesario apelar a esos mismos tropos para dar cuenta de su libertad combinatoria. Sin embargo, esta estrategia no parece estar disponible en este caso por una razón que el propio Lewis anticipó. Sucede que para que el principio de libre recombinación tenga vigencia (i) no es suficiente apelar a contrapartidas y (ii) es necesaria la existencia de relaciones externas. Esto se debe, por un lado, a que las contrapartidas están unidas simplemente por relaciones de semejanza, y dicha semejanza bien puede ser extrínseca; y, por otro lado, a que la distinción extrínseco/intrínseco sólo tiene sentido allí donde hay dos o más entidades externamente relacionadas. Por esto es que Lewis reemplaza contrapartidas por duplicados, donde un duplicado de $x$ es perfectamente semejante a $x$ en lo que respecta a sus propiedades intrínsecas (Lewis
} 
de tropos razonablemente ve en esto un problema: si la única razón para aceptar tropos no transferibles es que éstos bloquean el regreso de Bradley, y ello conlleva un mundo con tanta rigidez modal, cabe preguntarse si acaso existe una solución menos costosa, una solución que, evitando el regreso de Bradley, pueda también dar mayores grados de libertad modal.

Desde ya, cabe descartar una posible salida basada en la propuesta de Simons (1994), quien cree poder diluir la rigidez modal a la que nos llevan tropos no transferibles mediante la introducción de la distinción, para un mismo cúmulo, de cierta periferia accidental y cierto núcleo esencial. Mientras los tropos del núcleo esencial serían ontológicamente dependientes de manera recíproca y simétrica — de modo tal que ninguno de los tropos del núcleo podría existir sin los demás-, los tropos de la periferia accidental serían ontológicamente dependientes de una manera individual y asimétrica - de modo tal que cualquier tropo de la periferia necesita la existencia del núcleo para existir, pero el núcleo bien puede existir sin que ninguno de los tropos accidentales exista: al núcleo le basta con que otros tropos del mismo género o familia constituyan su periferia. Esta estrategia no hace más que introducir la dudosa distinción entre propiedades esenciales y accidentales sin siquiera bloquear el regreso de Bradley, pues, aun asumiendo que la distinción sea operativa, la solución simplemente hace que el problema de Bradley se desplace de un nivel a otro. Resuelto (supuestamente) el problema de la unidad a nivel nuclear, ¿cómo es que la periferia logra unirse al núcleo esencial de un mismo cúmulo? Si la distinción esencia/accidente ha de preservarse, entonces parece necesario invocar relaciones no supervinientes en la naturaleza de los relata para justificar su unidad contingente en un mismo cúmulo. $\mathrm{Y}$ sin una teoría sobre cómo estas relaciones rela-

1986, pp. 62-63, 88-89; cfr. Lewis 1983a, Lewis y Langton 1998). Pues bien, en la teoría de tropos no-transferibles aquí criticada, la noción de duplicado que Lewis utilizó resulta inaplicable y, por tanto, carece de los recursos necesarios para expresar libertad combinatoria. La duplicación de $x$ requiere poder distinguir aquello que $x$ es con independencia de estar solo o acompañado por otras entidades distintas. Pero en un mundo constituido exclusivamente por tropos no transferibles no es posible trazar con sentido dicha distinción, pues la existencia e identidad de cada tropo está determinada justamente por cuestiones que van más allá de él mismo (i.e., todos los demás tropos copresentes de los cuales su existencia e identidad depende), y, por lo mismo, no hay relación entre tropos cuya existencia e identidad sea independiente de la existencia e identidad de sus relata, y viceversa (i.e., no hay relaciones externas). Por esto no es extraño que algunos teóricos de tropos como Campbell (1990), consecuentemente, terminen tratando el mundo actual como un único gran cúmulo de tropos no-transferibles, adoptando un monismo cercano al de Spinoza. 
cionan núcleo esencial y periferia accidental, mal puede darse por superado el problema. Algo hace la diferencia entre el núcleo esencial unido a cierta periferia accidental y el núcleo esencial privado de dicha periferia accidental. Esa diferencia ha de estar dada porque, mientras en el primer caso hay una relación que de hecho relaciona núcleo y periferia, en el segundo no hay tal relación o dicha relación ha dejado de relacionar como de hecho lo hacía.

\section{Tropos transferibles en copresencia: la respuesta relacional}

Maurin (2010) cree tener la solución adecuada, una solución que, todavía dentro del marco de una ontología mono-categorial de tropos, supuestamente evita las rigideces modales de tropos no transferibles sin dejar de bloquear el regreso de Bradley. Su solución implica, sin embargo, aceptar tropos transferibles. Y, como es obvio, aceptar que Blancura 1 , Durezal y Dulzor ${ }_{1}$ son transferibles implica también aceptar que podrían existir y ser lo que son sin ser recíproca y específicamente dependientes, esto es, como cree el teórico de tropos, sin que la mera existencia de Blancura 1 , Dureza 1 y Dulzor ${ }_{1}$ entrañe la existencia de Terrón 1 . ¿Cómo garantizar entonces la existencia de Terrón ${ }_{1}$ ? Obviamente, parece necesario recurrir a la relación de copresencia, en este caso al tropo relacional Copresencial. Pero la invocación de Copresencia 1 abre la puerta a la amenaza de Bradley. Pues

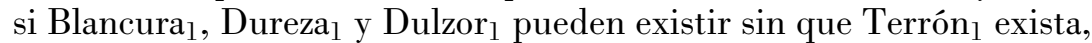
¿por qué la adición de Copresencia ${ }_{1}$ va a garantizar la existencia de Terrón $n_{1}$ ? ¿Cómo es que Copresencia ${ }_{1}$ hace una entidad a partir de relacionar tres? Maurin dice tener una explicación sobre cómo es que Copresencia ${ }_{1}$ hace el truco. Su propuesta descansa, en primer lugar, en una reformulación del problema de la unidad-compleja en términos de la búsqueda de hacedores de verdad capaces de garantizar la verdad de la proposición atómica que afirma la existencia del cúmulo relevante - en nuestro caso: $<$ Terrón $_{1}$ existe $>$. En segundo lugar, descansa en un refinamiento de la noción de dependencia ontológica que está en juego en Copresencia ${ }_{1}$. Como vimos, si los tropos que existen son transferibles, la mera existencia de Blancura ${ }_{1}$, Durezal y Dulzor $_{1}$ no garantiza la existencia de Terrón 1 y, por tanto, ellos no constituyen hacedores de verdad suficientes para garantizar la verdad de la proposición atómica $<$ Terrón $_{l}$ existe $>$. La propuesta de Maurin, entonces, consiste en postular la existencia del tropo Copresencia y comprenderlo como un tropo relacional cuya existencia depende múltiple y asimétricamente de sus relata, tal que: (i) Copresencial existe contingentemente; (ii) en caso de existir, Copresencia $a_{1}$ debe de 
hecho relacionar Blancura ${ }_{1}$, Dureza 1 y Dulzor ; $_{1}$ en otras palabras, no hay mundo posible donde Copresencia ${ }_{1}$ exista sin relacionar nada o donde relacione entidades distintas a las que de hecho relaciona; y (iii) Blancura, Dureza $_{1}$ y Dulzor $_{1}$ pueden existir sin estar relacionados por Copresencia 1 ; en otras palabras, hay al menos un mundo posible donde Blancura ${ }_{1}$, Dureza 1 y Dulzor ${ }_{1}$ existen y Copresencia no lo hace ( $c f r$. Maurin 2010, pp. 322-323). Siendo Copresencia 1 un tropo relacional, no parece ser víctima del regreso de Bradley, pues es incapaz de existir sin sus relata. En este sentido, se trataría, en la terminología tradicional, de una relación interna, una relación ontológicamente fundada en sus relata y que no representa adición ontológica independiente ( $c f r$. Armstrong 1978b, cap. 19; 1997, cap. 6; Lewis 1983b; Maurin 2010; Moore 1919; Mulligan 1998; Rorty 1967). De esta forma, Maurin parece hacer suyas las ideas generales de Simons $(2002 / 2003,2010)$ con respecto a tropos relacionales: un tropo relacional es "multidependiente" de sus relata, de modo tal que, por ejemplo, un tropo relacional binario necesariamente depende de dos relata, y estos dos relata "están relacionados de cierta forma en virtud de existir tal tropo dependiendo de ellos" (2002/2003, p. 6). Luego, si un tropo relacional existe, entonces, se supone, los relata de los cuales su existencia depende también existen y han de estar relacionados en la forma que dicho tropo relacional determina. La virtud adicional del tropo relacional Copresencia $a_{1}$ introducido por Maurin radica en que su dependencia ontológica es asimétrica. Es esto lo que supuestamente introduce la libertad modal que está ausente en un mundo de tropos no transferibles. Lo que hace Maurin es distinguir de manera más fina los distintos sentidos en que relata y relación pueden ser ontológicamente dependientes. Así, existe dependencia ontológica simétrica cuando los relata dependen conjuntamente de la relación y la relación depende de los relata. Y hay dependencia ontológica asimétrica cuando los relata dependen conjuntamente de la relación pero no la relación de los relata, ${ }^{7}$ o cuando la relación depende de los relata pero los relata no de la relación. Copresencia ${ }_{1}$ caería bajo esta segunda hipótesis de dependencia asimétrica. Si comprendemos Copresencia $a_{1}$ de esta forma, argumenta Maurin, su existencia garanti-

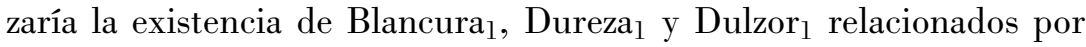

${ }^{7}$ Maurin señala que el caso de una relación que es capaz de existir sin relata le parece extraño y contraintuitivo, y lo incluye sólo por razones de completud lógica (cfr. 2010, p. 322n). Parece pasar por alto el hecho de que dicha posición ha sido explícitamente defendida por "estructuralistas ónticos" o "relacionalistas exclusivistas" como Dipert (1997) o Ladyman y Ross (2007). En estos casos, todo el trabajo ontológico fundamental es hecho por relaciones. 
ella, esto es, la existencia de Terrón ${ }_{1}$ y, por tanto, la verdad de la proposición $<$ Terrón $_{1}$ existe $>$. Pero, al mismo tiempo, se evitaría el mundo modalmente rígido al cual nos conducen tropos no transferibles, pues Blancura 1 , Dureza ${ }_{1}$ y Dulzor ${ }_{1}$ podrían existir sin que Terrón $_{1}$ existiera. Esto sucedería en todos los mundos posibles donde Copresencia $_{1}$ no existe y sí lo hacen Blancura ${ }_{1}$, Dureza 1 y Dulzor ${ }_{1}$, que no dependen de ella. Si, en cambio, Copresencia ${ }_{1}$ fuese simétricamente dependiente de Blancura ${ }_{1}$, Dureza y Dulzor $_{1}$, recurrir a ella sería una adición ontológica sin beneficios, pues nos conduciría al mismo mundo modalmente rígido al cual nos conducen los tropos Blancura $_{1}$, Dureza y Dulzor $_{1}$ cuando los comprendemos directamente como tropos no transferibles.

\section{6. ¿Tropos no transferibles al rescate?}

Pero las propuestas de los teóricos de tropos no resultan convincentes. Su gran error es que pretenden bloquear el regreso de Bradley mediante la incorporación de un ingrediente que implica una petición de principio que coincide perfectamente con la que Bradley describe como una explicación que "no dice nada en absoluto". Lo que hace el teórico de tropos es simplemente enriquecer la naturaleza de sus tropos monádicos con un tropo relacional o viceversa; es decir, evita el problema de fondo mediante la invocación de una virtus relativa que habitaría dentro de sus entidades favoritas, para luego concluir que la existencia de estas entidades es suficiente para garantizar la verdad de ciertas proposiciones relacionales. Esto es claro en el caso de teóricos de tropos mono-categoriales que conciben sus tropos como no transferibles. ¿Por qué, en el marco de dicha ontología, se sigue que si Blancura, Durezal y Dulzor ${ }_{1}$ existen, entonces Terrón ${ }_{1}$ existe? Simplemente porque, desde un inicio, cada uno de dichos tropos ha sido definido como ontológicamente dependiente de los demás que constituyen el cúmulo relevante: todos son recíprocamente dependientes. Se nos dice entonces que Blancura $($ o Durezal, o Dulzor 1 ) no

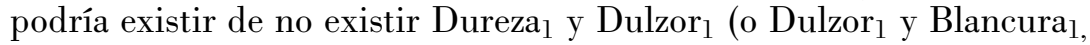
o Blancura 1 y Dureza 1 ), y que su dependencia recíproca garantiza la existencia de Terrón ${ }_{1}$. La respuesta directa al problema de Bradley se evita de la siguiente forma. Primero, se evita invocar una relación hacedora-de-uno de un modo abierto y explícito - es decir, se evita la invocación de una relación ontológicamente independiente o externa- y se nos dice entonces que se ha bloqueado la amenaza del regreso de Bradley. Segundo, al momento de explicar cómo es que Blancura ${ }_{1}$, Durezal y Dulzor $_{1}$ son idénticos a Terrón ${ }_{1}$ se nos 
dice que Terrón $n_{1}$ "superviene" o "no representa adición ontológica" a Blancura ${ }_{1}$, Dureza y Dulzor $_{1}$, que éstos no pueden sino dar lugar a Terrón ${ }_{1}$, que es de su naturaleza o esencia hacerlo, que simplemen-

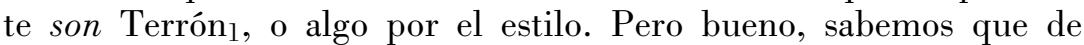
acuerdo con nuestro trilema ese "son" no puede ser una identidad de Terrón ${ }_{1}$ con cada una de sus cualidades por separado (primer cuerno), ni con todas ellas tomadas colectivamente (segundo cuerno). Sólo puede significar que Blancura ${ }_{1}$, Durezal y Dulzor ${ }_{1}$ están en una relación hacedora-de-uno. Pero, ¿qué ha hecho desaparecer la supuesta necesidad de recurrir a esa relación hacedora-de-uno? No el hecho de que las propiedades en cuestión sean ahora concebidas como tropos y no como universales, sino que en lugar de postular una relación externa se ha pasado a postular una relación interna, una relación inscrita en la naturaleza de los relata. Es decir, simplemente el hecho de que la relación ha sido incorporada a la naturaleza de cada propiedad, a lo que la propiedad es, y luego camuflada mediante un nombre que sugiere aparentemente una forma no relacional o "meramente formal" de convivencia: dependencia ontológica. Pero, como resulta evidente, dicha dependencia ontológica no tiene nada de no relacional, pues para que una entidad $x$ dependa ontológicamente de una entidad $y$, tanto $x$ como $y$ deben existir y ser entidades numéricamente distintas, y entre ambas debe mediar una - ¿¿qué más?!- relación de dependencia ontológica. ¿Y qué es lo que falta en esta explicación entonces? Lo obvio: si en dicha relación recae el trabajo explicatorio de la unidad de ciertos tropos, entonces se nos debe una explicación sobre cómo es que es capaz de relacionar sus términos. Como puede apreciarse, trasladar las relaciones a la naturaleza de los relata no da con el tipo de explicación buscada; es simplemente una respuesta que "no dice nada en absoluto", una respuesta que nos dice simplemente que ciertos relata están relacionados porque es de su naturaleza estar relacionados, porque tienen virtus relativa. Que la relación de dependencia ontológica recíproca en que habitan estos tropos no transferibles no sea externa no debe confundirnos; ahora el problema de Bradley ha sido trasladado al interior de cada propiedad:

Luego las cualidades deben ser, y deben también estar relacionadas. Pero luego hay una diversidad que cae al interior de cada cualidad. Cada una tiene un doble carácter, como soportando y como siendo constituida por la relación. ... [Y] la cuestión es cómo puede combinar esta variedad. (1930, p. 26) 
Es decir, los mismos problemas que nos trajo el terrón de azúcar nos los trae de vuelta cada propiedad - que suponíamos simple y monádica-, pues su esencia ahora es enriquecida con una relación. El tropo Blancura 1 ya no es simplemente Blancura, como suponíamos, y tampoco es sólo en-relación-con-Dureza-y-Dulzor ${ }_{1}$. Blancura 1 ha pasado a ser una unidad-compleja constituida relacionalmente: Blancura 1 -en-relación-hacedora-de-uno-con-Dureza 1 -y-Dulzor ${ }_{1}$.

\section{7. ¿Tropos transferibles al rescate?}

Y así como la respuesta del teórico mono-categorial de tropos no transferibles falla, también falla la propuesta del teórico mono-categorial de tropos transferibles, como es el caso de Maurin. La introducción de una relación de Copresencia 1 que dependa asimétricamente de los relata no hace más que restituir, en términos bastante misteriosos por lo demás, algo de la libertad modal perdida con tropos no transferibles, pero oculta el problema de Bradley de un modo análogo a como lo hace la propuesta anterior. Sucede que cuando se traduce el problema de Bradley en términos de la búsqueda de hacedores de verdad para la proposición atómica $<$ Terrón $_{l}$ existe $>$ parte del problema queda oculta. Se infiere de inmediato que la postulación de cualquier entidad capaz de garantizar la verdad de dicha proposición que no sea una relación externa constituye una respuesta satisfactoria. Vimos que eso es sólo una operación de encubrimiento, pues esa "cualquier entidad", si bien no constituye una relación externa, sí contiene una relación dentro de su naturaleza, dentro de lo que esa "cualquier entidad" es; y entonces el problema de Bradley no desaparece sino que se desplaza al interior de dicha entidad que, por incluir ahora una relación, deviene en una unidad-compleja. Y una vez en el interior de cada unidad-compleja enfrentaremos el mismo trilema al que nos conduce toda unidad-compleja. Y siendo que la única ruta aparentemente viable para solucionar el trilema es sostener que los constituyentes de la unidad-compleja son en una relación hacedorade-uno, quedamos frente al viejo dilema: o la relación hacedora-deuno relaciona porque tiene el poder de relacionar; o relaciona en virtud de otra relación, y esta relaciona en virtud de otra, ad infinitum.

En resumen: es evidente que el regreso se desencadena si es que Copresencia $_{1}$ es incorporada como una relación externa y luego intentamos responder a la pregunta sobre cómo relaciona diciendo que lo hace en virtud de otra relación del mismo tipo. También es evidente que no se desencadena dicho regreso si es que decimos que dicha relación externa relaciona porque relaciona. Pero claro, si bloqueamos 
de esta forma el regreso, ofrecemos una explicación que "no dice nada en absoluto". Pues bien, la sola invocación de una relación interna no cambia las cosas. Por un lado, una relación ontológicamente dependiente de la naturaleza de los relata no bloquea el regreso, pues se puede dar igualmente al interior de la entidad cuya naturaleza ha sido enriquecida con la relación si es que intentamos explicar, recurriendo a otra relación, cómo es que dicha relación relaciona sus términos. Por otro lado, si es que bloquea el regreso, entonces lo hace de la misma forma espuria en que una relación externa podría bloquearlo: diciendo que relaciona porque relaciona.

Parte de la confusión de Maurin tiene su explicación en cómo reformula el problema de Bradley. Pues el problema de Bradley no es si acaso Terrón ${ }_{1}$ existe; el problema es qué es Terrón, ${ }_{1}$, la definición real de Terrón ${ }_{1}$. La proposición cuya verdad debe probar Maurin no es (o al menos no directamente) < Terrón $n_{l}$ existe $>$, sino < Terrón es Blancura $_{1}$, Dureza y Dulzor $_{1}$ relacionados por Copresencia ${ }_{1}$, una relación hacedora-de-uno $>$. Detengámonos en lo que nos dice Maurin: Copresencia ${ }_{1}$ sería un tropo relacional cuya existencia depende de la existencia conjunta de Blancura, Dureza $_{1}$ y Dulzor ${ }_{1}$, pero no a la inversa; y de existir Copresencial, entonces debe relacionar Blancura $_{1}$, Durezal y Dulzor 1 . La idea central es que si Copresencia existe, entonces los objetos sobre los cuales depende deben estar relacionados en la forma en que Copresencia ${ }_{1}$ relaciona. Pero de estos postulados no se sigue que el problema de Bradley quede resuelto. Para empezar no es clara la diferencia entre un mundo en que Blancura $_{1}$, Dureza 1 y Dulzor ${ }_{1}$ existen sin que Copresencia ${ }_{1}$ exista y

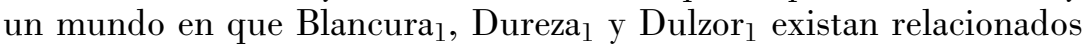
por Copresencia ${ }_{1}$. Claro, Maurin nos dice que mientras en el primer mundo la proposición $<$ Terrón $_{1}$ existe $>$ no es verdadera, en el segundo mundo sí lo es. Pero, ¿por qué? Bueno, porque, dada la existencia de Copresencial, entonces debe relacionar Blancura $a_{1}$, Durezal y Dulzor 1 como lo hace. Es decir, ¿cómo es que Copresencia 1 hace de Blancura 1 , Dureza y Dulzor $_{1}$ una unidad, cómo es que relaciona? Respuesta de Maurin: bueno, porque debe hacerlo, porque es de la esencia de Copresencia 1 relacionar los relata que relaciona. Ésta es exactamente la petición de principio de la que habla Bradley. La explicación de Maurin no explica nada; solo pone fin al problema por decreto. ${ }^{8}$

${ }^{8}$ Por análogas razones es que propuestas como las de Alvarado (2014) y Ehring (2011) fallan como explicaciones. Alvarado cree bloquear el regreso apelando a un tropo de ser que es "esencialmente" la instanciación de tal universal por tal par- 
La única supuesta ventaja de la solución de Maurin es que, en tanto concibe Copresencia ${ }_{1}$ como una relación que depende solo asimétricamente de los relata, introduce grados razonables de libertad modal para los relata. La única diferencia ahora es que mientras que se supone es de la esencia de Copresencia relacionar Blancura ${ }_{1}$, Dureza y Dulzor ${ }_{1}$, no es de la esencia de Blancural, Durezal y Dulzor ${ }_{1}$ estar en relación de Copresencia. Pero, ¿qué quiere decir esto sino que Copresencia ${ }_{1}$ es simplemente accidental a Blancura ${ }_{1}$, Dureza 1 y Dulzor $_{1}$ ? Y si éste es el caso, entonces el problema de Simons (1994) es ahora el mismo problema que debe enfrentar Maurin. Como vimos, uno de los problemas de Simons es que la distinción entre núcleo esencial y periferia accidental produce un desplazamiento del problema de Bradley: ¿cómo unir en una misma entidad aquello que es accidental con aquello que es esencial? En el caso de Maurin, la pregunta es casi la misma: ¿cómo es que una capa ontológica accidental o periférica (Copresencia ${ }_{1}$ ) pasa a inherir en varios núcleos esenciales (Blancura 1 , Durezal, Dulzor 1 )? No puede ser que inhiera en cada uno de ellos por separado (primer cuerno); tampoco puede ser que inhiera en ellos colectivamente (segundo cuerno); finalmente, tampoco puede ser que inhiera en ellos mediante una relación-hacedora-de-uno, pues esta relación relaciona en virtud de que relaciona (petición de principio) o en virtud de otra relación hacedora-de-uno (regreso vicioso).

Por lo anterior es que tampoco son iluminadores los intentos de reemplazar (o encubrir) la idea irremediablemente relacional de dependencia ontológica mediante el uso de fórmulas que apelen puramente a las consecuencias modales de dicha relación. Pues del hecho de que Copresencia ${ }_{1}$ coexista necesariamente con Blancura ${ }_{1}$, Dureza y Dulzor, , es decir, del hecho de que no haya mundo posible donde

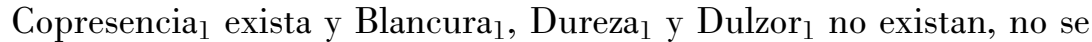
sigue en absoluto que dichos tropos están de hecho relacionados por Copresencia ${ }_{1}$, esto es, que esas entidades necesariamente coexistentes sean Terrón $\mathrm{n}_{1}$. La mera coexistencia necesaria de varios objetos no es sinónimo de que dichos objetos constituyan un mismo objeto, que sean una unidad-compleja por oposición a una mera pluralidad. Pensemos en la existencia del individuo Sócrates y del conjunto \{Sócrates $\}$. No hay mundo donde uno exista sin el otro. Sin embargo, no diremos que Sócrates es un conjunto; ser un conjunto no es parte

ticular. Ehring cree bloquear el regreso apelando a una relación de copresencia "autorrelacional". Ambas estrategias asumen lo que Bradley está poniendo en discusión: la capacidad de relacionar de una relación. Ambas soluciones incurren en la petición de principio según la cual las relaciones relacionan porque tienen virtus relativa. 
de la definición real, de la identidad, de lo que el individuo Sócrates es. O, para ser más claros, pensemos en el número 4 y la forma platónica de la Justicia. Si ambos objetos existen, se supone, coexisten necesariamente: en todo mundo donde existe el número 4 existe la Justicia. Pero el número 4 no es la Justicia. Ambos son objetos distintos. En principio, ambos parecen coexistir sin que medie entre ellos una relación hacedora-de-uno. Y es que si bien podemos inferir ciertas conexiones necesarias a partir de lo que un objeto es, no podemos inferir lo que un objeto es a partir de ciertas conexiones necesarias ( $c f r$. Fine 1994). Luego, la existencia de conexiones necesarias entre un objeto $x$ y un objeto $y$, aparte de ser prima facie misteriosas, no aseguran que $x$ e $y$ efectivamente constituyan una unidad-compleja. Así, del hecho que Copresencia ${ }_{1}$ coexista necesariamente con Blancura ${ }_{1}$, Dureza 1 y Dulzor ${ }_{1}$ no podemos inferir nada sobre lo que estos constituyentes son, ni, por tanto, sobre cómo es que Copresencia ${ }_{1}$ de hecho relaciona Blancura, , Dureza y Dulzor 1 .

Finalmente, la solución de Maurin adolece de un obvio problema de circularidad. Para explicar por qué Blancura ${ }_{1}$, Dureza 1 y Dulzor $_{1}$ son Terrón $n_{1}$ se ha invocado la relación Copresencia. . Pero Copresencia $_{1}$, a su vez, depende de Blancura ${ }_{1}$, Dureza 1 y Dulzor . $_{\text {. }}$ Pues bien, ¿cómo puede Copresencia ${ }_{1}$ constituir el fundamento onto-

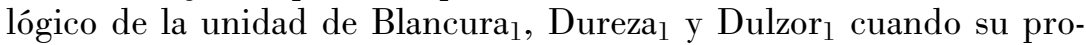
pia existencia depende de la existencia Blancura ${ }_{1}$, Dureza ${ }_{1}$ y Dulzor D $_{1}$ ? ¿Qué hace, por decirlo así, que de todos los mundos donde Blancura 1 , Dureza $_{1}$ y Dulzor D $_{1}$ existen, en algunos de ellos estos tropos no den lugar a Copresencia 1 y en otros sí? ¿Por qué en algunos mundos sus naturalezas simples se vuelven complejas y eso los lleva a dejar de ser una mera pluralidad? Asumiendo que han dado lugar a la existencia de Copresencia ${ }_{1}$, ¿cómo es que ellos son ellos mismos y a la vez son ellos mismos en Copresencia ?

\section{Bradley reivindicado}

El error de Maurin bien puede tener su origen en un error de diagnóstico. Ella estima que Bradley estuvo en lo correcto al sostener (i) que la relación que se da entre las propiedades que constituyen un objeto complejo no puede ser interna, y (ii) que las relaciones externas traían consigo un regreso vicioso. Sin embargo, Bradley se habría equivocado al concluir (iii) que ninguna relación puede expli-

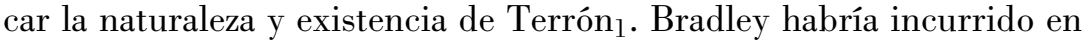
este último error, según Maurin, por no haber hecho una distinción más refinada de las formas en que una relación y sus relata pueden 
ser dependientes, como sí lo hace ella (cfr. 2010, p. 322). Pero como se puede inferir de lo que he argumentado, este triple diagnóstico está lejos de ser acertado. En cuanto a (i), Bradley ciertamente afirmaría que la relación entre las propiedades que constituyen un objeto complejo no puede ser interna, pero no por las razones que cree Maurin. Ella sostiene que dicha relación no puede ser interna si es que por ello se entiende una relación donde existe dependencia ontológica simétrica entre la relación y los relata, es decir, donde ella depende de sus relata y los relata dependen de ella, pues eso nos conduciría al escenario modalmente rígido e indeseable de los tropos no transferibles ( $c f r .2010$, p. 322n). Pero nada más lejos de las preocupaciones de Bradley. Bradley estaba muy poco interesado en las consecuencias modales que se siguiesen de la constitución de un objeto y, ciertamente, no se habría preocupado mucho si este mundo no pudiese ser de otra forma que como de hecho es si es que ello significaba dar solución al problema de la unidad-compleja ( $c f r$. Candlish 2007, cap. 6). La razón de su rechazo a las relaciones internas es simplemente la misma que lo lleva a rechazar las relaciones externas: ambas son incoherentes; ninguna puede lograr real unidad; ninguna de hecho relaciona. Para Bradley, toda relación, sea externa o interna, es básicamente apariencia, pues ninguna es capaz de lograr la unidad no relacional fundamental (cfr. 1914, pp. 237-240; 1930, Apéndice B; 1935, pp. 641-646 y 665-668); todas ellas son "la expresión inadecuada de una unidad subyacente" (1930, p. 522). Y esto aplica a cualquier forma de dependencia ontológica, sea simétrica o asimétrica, en tanto ella siempre encubre una relación entre entidades numéricamente distintas. Esto explica también que Maurin se equivoque en (ii), pues el regreso de Bradley no sólo surge cuando estamos frente a relaciones externas; también surge cuando la relación es interna. Pues entonces el problema de la unidad-compleja se traslada al interior de al menos uno de los constituyentes, antes simple y ahora complejo, y se suscitará a su respecto el mismo trilema que suscita cualquier unidad-compleja. Y si uno estima que su unidad está dada por una relación hacedora-de-uno, entonces uno se verá enfrentado siempre a un regreso o a una petición de principio. A lo primero, si es que uno sostiene que las relaciones (sean externas, sean internas) relacionan en virtud de otra relación (sea externa, sea interna); a lo segundo, si es que uno sostiene que las relaciones (sean externas, sean internas) relacionan porque tienen el poder de relacionar. De ahí entonces que Bradley no pudo sino concluir (iii). 


\section{9. ¿Qué hacer?}

Cualquiera que haya intentado responder la pregunta por la naturaleza última de algo tenderá a estar de acuerdo con lo que sostiene Lewis:

Un esfuerzo en filosofía sistemática debe en efecto dar cuenta de cualquier supuesto hecho. Hay tres maneras de hacer esto. (1) "Lo niego" - esta manera es reprobada en caso de que el hecho es realmente mooreano. (2) "Lo analizo así" [... ]. O (3) "Lo acepto como un primitivo". "¡No todo dar cuenta de algo es un análisis!”. (1983b, p. 352)

Esto también parece indiscutible tratándose las posibles salidas al desafío de Bradley. ${ }^{9}$ Veamos.

El camino (1) ("Lo niego") es el que abrazó Bradley en sus momentos más oscuros. Es decir, negó la realidad mooreana de Terrón y aceptó las consecuencias que parecen seguirse de su reductio: la realidad es una unidad indiferenciada, y el pluralismo y las relaciones son sólo apariencia (1930, caps. 13-14). Pero esta salida está cruzada por una enorme tensión interna. Si el pluralismo y las relaciones han sido relegados al ámbito de las apariencias, ¿̨cómo es que estos dos ámbitos, apariencias y realidad, conviven sino es mediante una o más relaciones? ¿Y cómo es que apariencias y realidad no constituyen entonces una unidad-compleja? El ascenso al Absoluto, la unidad norelacional donde toda relación supuestamente es trascendida, exige la inclusión de relaciones y de pluralidad dentro del inventario de la

${ }^{9}$ Un árbitro me sugiere que existe una cuarta alternativa: que sea la "ciencia fundamental", y no la metafísica, la encargada de explicar la composición de objetos ordinarios y la instanciación de propiedades. Pero no parece haber lugar para semejante alternativa. Pues si una teoría que encarna esa "ciencia fundamental" es entendida en términos realistas, entonces inevitablemente deviene en alguna forma de teoría metafísica comprometida con la existencia de una realidad última que trasciende y al mismo tiempo (se supone) explica las apariencias (e.g., variables ocultas, etc.). Y si, por el contrario, dicha teoría es entendida en términos antirrealistas, entonces ni siquiera pretende que la tomemos como una imagen verdadera del mundo, sino sólo como una imagen útil, empíricamente adecuada (que "salva los fenómenos"), o algo en esas líneas. ( $c f r$. van Fraassen 1980, §§ 1.1-l.2). En el mismo sentido, Bradley: "El objeto de la ciencia natural no es la determinación de la verdad última, y su provincia no se expande más allá de los fenómenos. [...] La cuestión no es si acaso los principios de la ciencia física poseen una verdad absoluta a la cual no aspiran. La cuestión es si acaso la abstracción, empleada por tal ciencia, es legítima y útil.” (1930, pp. 250-25l) Así, si el objetivo de la ciencia es la verdad última, entonces deviene en metafísica; si se restringe a los fenómenos, entonces no pretende dar con la verdad última. 
existencia, al menos provisoriamente, como un peldaño de la escalera a ser arrojada (cfr. Blanshard 1984). ${ }^{10}$ Por su parte, el camino (2) ("Lo analizo así") es el camino que ha sido tomado por los metafísicos que aceptan las premisas del argumento de Bradley pero se resisten a sus consecuencias, entre ellos los teóricos de tropos aquí criticados. Como la idea de los análisis alternativos que ellos proponen es evitar contradicciones o falsedades sin negar los hechos mooreanos que Bradley estuvo dispuesto a negar, se ven obligados a elegir el tercer cuerno para dar cuenta de Terrón ${ }_{1}$ : recurrir a una relación hacedora-de-uno. Entonces nos damos cuenta de que sus análisis nunca explican o terminan invocando en su explicación lo que pretendían explicar. No nos dan lo que nos prometen. No comprendemos cómo es posible una unidad-compleja mejor de lo que comprendíamos esa posibilidad antes de emprender el análisis.

¿Es entonces el camino (3) ("Lo acepto como un primitivo") nuestra vía de escape? Me parece que sí, pero de una manera distinta a como suele entenderse. Hay al menos dos formas de entender el primitivismo. Una primera forma es la que llamaré primitivismo ontológico. Para esta forma de primitivismo, los primitivos serían aquellas entidades fundamentales que figuran en ese inventario completo y no redundante al cual aspira llegar el metafísico. Los primitivos serían elementos simples, básicos, irreductibles, elementos que por su naturaleza no resisten mayor análisis pero que supuestamente nos sirven para explicar la naturaleza de cosas complejas. Una segunda forma de primitivismo es la que podría llamar primitivismo mooreano, pero que llamaré primitivismo negativo, por razones que explicaré en seguida. Este primitivismo se contenta con el nivel de las abundantes y complejas apariencias, nivel que no parece habitado por los primitivos de los que nos habla el primitivismo ontológico. Es el primitivismo negativo la solución que creo deberíamos abrazar.

Sucede que cuando por hipótesis estamos frente a una unidadcompleja de estatus mooreano, como lo es Terrón ${ }_{1}$, el metafísico no puede, sin traicionar el objetivo de su empresa (i.e., desentrañar la naturaleza última de las cosas), aceptar el camino (3) de Lewis sino como una sugerencia pragmática. Uno bien puede decir que no es posible dar una explicación de todo, o que las explicaciones han de

${ }^{10}$ Contra lo que algunos creen, abrazar ya no el monismo sino el pluralismo, es decir, negar Terrón 1 por la vía de aceptar el segundo cuerno del trilema de Bradley (i.e., Terrón $n_{1}$ es mera pluralidad), no es una alternativa viable si el argumento de Bradley demuestra la incoherencia de las relaciones, pues todo pluralismo, como bien lo entendió Russell, va acompañado de algún tipo de relaciones ( $c f r$. Russell 1956, p. 333). 
terminar en alguna parte, pero esas respuestas, perfectamente aceptables en contextos ordinarios, son, dentro de la empresa metafísica que pretende dar cuenta de Terrón ${ }_{1}$, admitir una derrota antes de la batalla. Y es que la empresa metafísica comienza justo ahí donde termina el mooreanismo. Comienza porque para el metafísico las apariencias supuestamente requieren una explicación. Sólo entonces estamos frente a las tres opciones de Lewis. Un terrón de azúcar, aun cuando sí es de aquellas cosas cuya realidad el mooreano acepta sin dudar, no es de aquellas cosas cuya realidad el metafísico acepta (o rechaza) sin previo análisis. Por hipótesis, no es algo así como un ladrillo fundamental de la realidad como los que tiene en mente el metafísico cuando elige sus primitivos, pues evidentemente es una entidad compleja. Análogamente, el metafísico no aceptará la verdad de la afirmación "¡He aquí una mano!” sin previo análisis. Antes de asentir, considerará fundamental determinar qué es, últimamente, una mano (¿una colección de datos de los sentidos?, ¿un conjunto de átomos materiales simples dispuestos-en-forma-de-mano?, ¿un modo del divino atributo de lo extenso?, etc.). Sólo con criterios de identidad últimos obtendrá satisfacción intelectual y podrá asentir. De ahí entonces que, frente a una unidad-compleja como Terrón ${ }_{l}$, al metafísico no le resulte tolerable el camino (3), y sólo le quede o aceptar el camino (1) y negar un hecho mooreano, o seguir el camino (2) y proceder a analizarlo hasta llegar a un primitivo más respetable, uno digno del primitivismo ontológico. Pero en este análisis está condenado a fallar, como lo prueba Bradley.

En contraste, el primitivismo negativo no cree que Terrón ${ }_{1}$ necesite una explicación sobre su naturaleza última. Terrón ${ }_{1}$ es una unidadcompleja, es real y es de ciertas maneras, pero no posee la naturaleza última que busca el metafísico. Cuando definimos una determinada unidad-compleja como una pluralidad en relación hacedora-de-uno, no explicamos lo que la unidad-compleja es en términos últimos, pues no ofrecemos un análisis, supuestamente revelador y profundo, en el cual no vuelva a figurar, explícita o implícitamente, el analysandum. Esta forma de primitivismo parece hace suyo el realismo ingenuo y directo que subyace al dictamen de Wittgenstein: "Puesto que todo está abierto a la vista no hay nada que explicar" (2001, § 126). Las apariencias sólo cabe describirlas, no explicarlas. Pero Wittgenstein también sostuvo que "lo que está oculto no nos interesa" (ibid.) y que la buena filosofía "deja todo tal cual como es" (2001, § 126). $\mathrm{Y}$ estos dos últimos dictámenes no siempre van de la mano con el primero, pues si hay algo oculto, entonces el mero desinterés en ello no es suficiente para desactivar de raíz el primitivismo ontológico, 
así como tampoco una buena filosofía puede dejar todo tal cual es si es que ese todo ya ha sido infectado por mala filosofía. Hay que encontrar un correlato metafísico para el primer dictamen de Wittgenstein. Hasta donde alcanzo a ver, ese correlato existe en al menos una metafísica, la de Nāgārjuna. La pregunta por la naturaleza última de las cosas supone que las cosas tienen una naturaleza última. La metafísica de Nāgārjuna justamente niega dicho supuesto: las cosas son y son de muchas maneras, pero carecen de naturaleza última, carecen de svabhāva. Se trata de una metafísica negativa, una metafísica de la vaciedad (śūnyatā) (cfr. Siderits y Katsura 2013; Westerhoff $2009,2010)$. Y lo que vale para todas las cosas vale también para el es que figura en toda definición real. Si la realidad es como la entiende Nāgārjuna, entonces una empresa cuyo giro es la búsqueda de naturalezas últimas está destinada al fracaso.

La articulación detallada de una solución basada en los principios recién esbozados excede con creces el objetivo central de este artículo y deberá quedar pendiente para otra ocasión. Pero cualquiera que sea la solución al desafío de Bradley, creo que debe satisfacer al menos dos condiciones que el primitivismo negativo sí satisface: (i) No puede constituir una claudicación frente a Bradley. Aunque no sepamos qué ni dónde, tiene que haber algo errado en el argumento de Bradley, pues tanto unidades-complejas como relaciones son esenciales para pensar y para dar cuenta de las apariencias, tanto o más indispensables que las matemáticas para el físico ( $c f r$. MacBride $2016, \S 2)$. Apostar por una realidad que traiciona de una forma tan radical esas apariencias y que, peor aún, también se ve forzada a incluirlas, no es una apuesta sensata. (Aunque, por supuesto, del hecho de que Bradley debe estar equivocado en alguna parte no se sigue ninguna solución en particular.) (ii) Debe tomar en consideración que el argumento de Bradley afecta el núcleo central de la empresa metafísica tradicional: el significado del es que figura en todo enunciado de identidad explicatorio último, en toda definición real. Si el argumento funciona y no estamos dispuestos a claudicar frente a él, es porque en realidad hay algo profundamente errado en la metafísica tradicional. Si descubrimos por qué el argumento falla, es porque hemos descubierto no una solución a un problema local sino una forma distinta de hacer metafísica. El argumento no puede ser desactivado localmente, pues eso supone hacer uso de los mismos recursos cuya legitimidad Bradley está poniendo en cuestión. Sólo puede ser desactivado globalmente, poniendo en cuestión los presupuestos tradicionales de la empresa metafísica, notoriamente dos: en primer lugar, que las cosas tienen una naturaleza última que explica 
lo que son manifiestamente; en segundo lugar, que las apariencias mooreanas necesitan ser explicadas, esto es, que no basta con la mera descripción de lo que está frente a nosotros sino que requerimos invocar una razón suficiente que explique por qué dichas apariencias mooreanas deben ser como de hecho son. ${ }^{11}$

\section{BIBLIOGRAFÍA}

Alvarado, J.T., 2014, “Estados de cosas y relaciones de fundación”, Tópicos, no. 28 , pp. $1-31$.

Armstrong, D.M., 1997, A World of States of Affairs, Cambridge University Press, Cambridge.

- 1978a, Universals and Scientific Realism I: Nominalism and Realism, Cambridge University Press, Cambridge.

— 1978b, Universals and Scientific Realism II: A Theory of Universals, Cambridge University Press, Cambridge.

Basile, P., 1999, Experience and Relations: An Examination of F.H. Bradley's Conception of Reality, Verlag Paul Haupt, Bern.

Baxter, D., 1996, "Bradley on Substantive and Adjective: The ComplexUnity Problem", en W.J. Mander (ed.), Perspectives on the Logic and Metaphysics of F.H. Bradley, Thoemmes Press, Bristol, pp. 1-24.

—_, 1988, "Many-One Identity", Philosophical Papers, vol. 17, no. 3, pp. 193-216.

Blanshard, B., 1984, "Bradley on Relations", en A. Manser y G. Stock (eds.), The Philosophy of F.H. Bradley, Clarendon Press, Oxford, pp. 211-226. Bonino, G., 2013, "Bradley's Regress: Relations, Exemplification, Unity", Axiomathes, vol. 23, pp. 189-200.

Bradley, F.H., 1935, "Relations", en sus Collected Essays, vol. 2, Clarendon Press, Oxford, pp. 629-676.

—_, 1930, Appearance and Reality, 2a ed., 9a imp., Clarendon Press, Oxford.

- 1914, Essays on Truth and Reality, Clarendon Press, Oxford.

Campbell, K., 1990, Abstract Particulars, Basil Blackwell, Oxford.

Candlish, S., 2007, The Russell/Bradley Dispute and Its Significance for Twentieth-Century Philosophy, Palgrave Macmillan, Nueva York, Nueva York.

Dipert, R., 1997, "The Mathematical Structure of the World: the World as Graph", Journal of Philosophy, vol. 94, no. 7, pp. 329-58.

${ }^{11}$ Agradezco a dos árbitros anónimos de Crítica por sus sugerencias, y a José Tomás Alvarado y Javier Vidal por sus observaciones a una versión preliminar de este artículo, presentada en la Universidad de Concepción. Finalmente, agradezco a Stephen Barker por haberme introducido en la fascinante metafísica negativa de Nāgārjuna. El presente artículo ha sido escrito dentro del marco del proyecto de investigación VRID-Iniciación 215.063.012-1.0IN (Universidad de Concepción). 
Ehring, D., 2011, Tropes: Properties, Objects, and Mental Causation, Oxford University Press, Oxford.

Fine, K., 1995, "Ontological Dependence", Proceedings of the Aristotelian Society, New Series, vol. 95, pp. 269-290.

__, 1994, "Essence and Modality", Philosophical Perspectives, vol. 8, pp. 1-16.

Gaskin, R., 2008, The Unity of the Proposition, Oxford University Press, Oxford.

Grossmann, R., 1982, "Review: D.M. Armstrong, Universals and Scientific Realism Volume 1: Nominalism and Realism; Volume 2: A Theory of Universals; both vols. (Cambridge, 1978)", Noûs, vol. 16, no. 1, pp. 133142.

Hylton, P., 1990, Russell, Idealism, and the Emergence of Analytical Philosophy, Clarendon Press, Oxford.

Ladyman, J. y D. Ross, 2007, Every Thing Must Go: Metaphysics Naturalized, Oxford University Press, Oxford.

Lewis, D., 1986, On the Plurality of Worlds, Blackwell, Oxford.

—_, 1983a, "Extrinsic Properties", Philosophical Studies, vol. 44, no. 2, pp. 197-200.

- $1983 \mathrm{~b}$, "New Work for a Theory of Universals", Australasian Journal of Philosophy, vol. 61, no. 4, pp. 343-377.

Lewis, D. y R. Langton, 1998, "Defining "Intrinsic"”, Philosophy and Phenomenological Research, vol. 58, no. 2, pp. 333-345.

MacBride, F., 2016, "Relations", The Stanford Encyclopedia of Philosophy (Primavera 2016), E.N. Zalta (ed.), <http://plato.stanford.edu/archives/ spr2016/entries/relations/> < http://plato.stanford.edu/archives/spr2016/ entries/relations/ $>$ [fecha de última consulta: 25/05/2016].

—_, 2011, "Relations and Truthmaking II", Proceedings of the Aristotelian Society, vol. 111, pp. 161-79.

Maurin, A-S., 2012, “Bradley's Regress", Philosophy Compass, vol. 7, no. 11, pp. 794-807.

—_, 2010, "Trope Theory and the Bradley Regress", Synthese, vol. 175, pp. 311-326.

Molnar, G., 2003, Powers: A Study in Metaphysics, Oxford University Press, Oxford.

Moore, G.E., 1919, "External and Internal Relations", Proceedings of the Aristotelian Society, New Series, vol. 20, pp. 40-62.

Morganti, M., 2014, "Metaphysical Infinitism and the Regress of Being", Metaphilosophy, vol. 45, no. 2, pp. 232-244.

Mulligan, K., 1998, "Relations-Through Thick and Thin", Erkenntnis, vol. 48, no. 2, pp. 325-353.

Orilia, F., 2009, “Bradley's Regress and Ungrounded Dependence Chains: A Reply to Cameron", Dialectica, vol. 63, no. 3, pp. 333-341.

Rorty, R., 1967, "Relations, External and Internal", en P. Edwards (ed.), The Encyclopedia of Philosophy, vol. 7, Macmillan Company, Nueva York, Nueva York, pp. 125-133. 
Russell, B., 1956, "Logical Atomism", en su Logic and Knowledge, George Allen and Unwin, Londres, pp. 321-343.

Schaffer, J., 2010, "Monism: The Priority of the Whole", Philosophical Review, vol. 119, no. 1, pp. 31-76.

- - 2009, "On What Grounds What", en D. Chalmers, D. Manley y R. Wasserman (eds.), Metametaphysics, Oxford University Press, Oxford, pp. 347-383.

Siderits, M. y S. Katsura, 2013, Nāgārjuna's Middle Way, Wisdom, Somerville, Mass.

Simons, P., 2010, "Relations and Truthmaking I", Proceedings of the Aristotelian Society Supplementary Volume, vol. 84, pp. 199-213.

—_, 2002/2003, "Tropes, Relational", Conceptus, vol. 35, pp. 53-73.

_- 1994, "Particulars in Particular Clothing: Three Trope Theories of

Substance", Philosophy and Phenomenological Research, vol. 54, no. 3, pp. 553-575.

Sprigge, T., 1983, The Vindication of Absolute Idealism, Edinburgh University Press, Edimburgo.

Strawson, P.F. [1959] 2003, Individuals: An Essay in Descriptive Metaphysics, Routledge, Londres.

Vallicella, V., 2002, "Relations, Monism and the Vindication of Bradley's Regress", Dialectica, vol. 56, no. 1, pp. 3-35.

van Fraassen, B., 1980, The Scientific Image, Clarendon Press, Oxford.

Westerhoff, J., 2010, Nāgārjuna's Vigrahavyāvartani: The Dispeller of Disputes, Oxford University Press, Oxford.

—— 2009, Nāgārjuna's Madhyamaka, Oxford University Press, Oxford.

Williams, D.C., 1953, "On the Elements of Being I-II", The Review of Metaphysics, vol. 7, nos. 2-3, pp. 3-18, 171-192.

Wittgenstein, L., 2001, Philosophical Investigations, G.E.M. Anscombe (trad.), 3a ed., Blackwell, Oxford.

Recibido el 14 de agosto de 2015; revisado el 12 de enero 2016; aceptado el 5 de mayo de 2016. 